\title{
Comparing Bispectral Index and Narcotrend monitors in patients undergoing major hepatobiliary surgery: a case series
}

This article was published in the following Dove Press journal:

Clinical Audit

\author{
Charlotte Davies' \\ Katyayani Katyayani ${ }^{2}$ \\ Gudrun Kunst ${ }^{2}$ \\ Charles C Taylor ${ }^{3}$ \\ Yiyan Wang ${ }^{3}$ \\ Stuart Barber ${ }^{3}$ \\ Zoka Milan ${ }^{2}$
}

'Brighton and Sussex Medical School, Brighton, UK; ${ }^{2}$ Anaesthetic Department, King's College Hospital, London, UK; ${ }^{3}$ Leeds School of Mathematics, Leeds, UK

Correspondence: Zoka Milan

Anaesthetic Department, King's College Hospital, Denmark Hill, London SE5 9RS, UK

Tel +442032999000

Emailzoka.milan@nhs.net

\begin{abstract}
Intraoperative monitoring of brain electrical activity is the standard of care for major surgical procedures. Although UK national suggested that the Bispectral Index (BIS) and Narcotrend (NCT) depth-of-anesthesia monitors are broadly equivalent, there is contradictory evidence in the literature comparing the two monitors. In this case series, we present a comparison between BIS and NCT indices recorded in 20 patients undergoing major hepatobiliary surgery. A total of 52,562 data pairs were obtained from 20 patients. Each index was then categorized according to whether the value was below, within, or above the target range (40-60 for BIS and 27-64 for NCT). Our results indicated discordance in the clinical guidance provided by these monitors in $29.3 \%$ of cases. Different timing of data collection between the two monitors and electrode position may have contributed to these findings. These observations mean that we cannot fully rely on electroencephalography monitoring to determine the depth of anesthesia. Therefore, it is important for the anesthetist continually to perform comprehensive assessment of the depth of anesthesia, including use of depth-of-anesthesia monitors, review of clinical signs, and use of monitored anesthesia carebased techniques where appropriate. In addition, monitoring of relative changes in the BIS: NCT index ratio over time would be more clinically useful than recording absolute values.
\end{abstract}

Keywords: monitoring, cerebral, hepatobiliary, awareness, depth of anesthesia, adult

\section{Introduction}

Current evidence suggests that anesthesia that is either excessively deep or too light may have a negative impact on patient outcomes. While awareness during general anesthesia is associated with patient dissatisfaction and increased incidence of posttraumatic stress disorder, excessive depth has been linked to increased incidence of postoperative delirium and cognitive dysfunction. ${ }^{1-4}$ In addition, some studies have also suggested an association between excessive depth of anesthesia and postoperative mortality. ${ }^{5,6}$ However, this hypothesis has been widely debated.

Traditional methods of monitoring depth of anesthesia have been based on clinical signs and minimal alveolar concentration of inhalational anesthetics. Advances in technology over the last 20 years have led to the development of electroencephalography (EEG)-based depth-of-anesthesia monitors. The first commercially available EEG monitor was the Bispectral Index (BIS; Aspect Medical Systems, Norwood, MA, USA), which was introduced in 1992. The Narcotrend (NCT) monitor, developed at the University Medical School of 
Hanover (Monitor Technik, Bad Bramstedt, Germany) and introduced in 2001, is a major competitor.

Since their introduction, several studies have evaluated the clinical potential and cost-effectiveness of EEG-based depth-of-anesthesia monitors. While some studies have demonstrated reductions in incidence rates of awareness and cognitive impairment with the use of such monitors, others have failed to replicate the results. ${ }^{4,7-12}$

Major hepatobiliary surgeries often involve long surgical times in very high-risk patients and the use of neuromuscular blockade. The National Institute for Health and Care Excellence (NICE) guidelines recommended the use of EEG-based depth-of-anesthesia monitors to maintain adequate anesthetic depth and positive patient outcomes in such surgeries. ${ }^{13}$

Although NICE 2012 suggested that BIS and NCT depth-of-anesthesia monitors are broadly equivalent, ${ }^{14}$ there is contradictory evidence in the literature comparing the two monitors. ${ }^{15-23}$

In this case series, we present a comparison between BIS and NCT indices recorded in 20 patients undergoing major hepatobiliary surgery under general anesthesia with neuromuscular blockade.

\section{Case series}

The NHS Health Research Authority Ethics Committee waived the need for ethics committee approval based on the facts that participants were not randomized in different groups and the study protocol did not demand changing treatment/patient care from accepted standards for any of the patients involved. Patients' written consent was not required. This audit was performed in compliance with the Declaration of Helsinki. Twenty patients who underwent major hepatobiliary surgery between January and March 2017 were included in the case series.

All patients received $0.03-0.05 \mathrm{mg} / \mathrm{kg}$ midazolam intravenously prior to induction of anesthesia with propofol $(1-2 \mathrm{mg} / \mathrm{kg})$ and fentanyl $(2-5 \mu \mathrm{g} / \mathrm{kg})$ intravenously. Following loss of consciousness, patients received 0.5-0.7 $\mathrm{mg} / \mathrm{kg}$ atracurium for muscle relaxation. Anesthesia was maintained intraoperatively with desflurane. Intraoperative analgesia was provided with epidural infusion of bupivacaine $0.25 \%+$ diamorphine $0.1 \mathrm{mg} / \mathrm{mL}$ and/or intravenous remifentanil infusion at $0.1-1 \mu \mathrm{g} / \mathrm{kg} / \mathrm{min}$.

Prior to induction of anesthesia, the patient's forehead skin was prepared with an abrasive gel (Nuprep; Dow Weaver, Aurora, CO, USA). Monitoring electrodes for both BIS (Coviden, Mansfield, MA, USA) and NCT

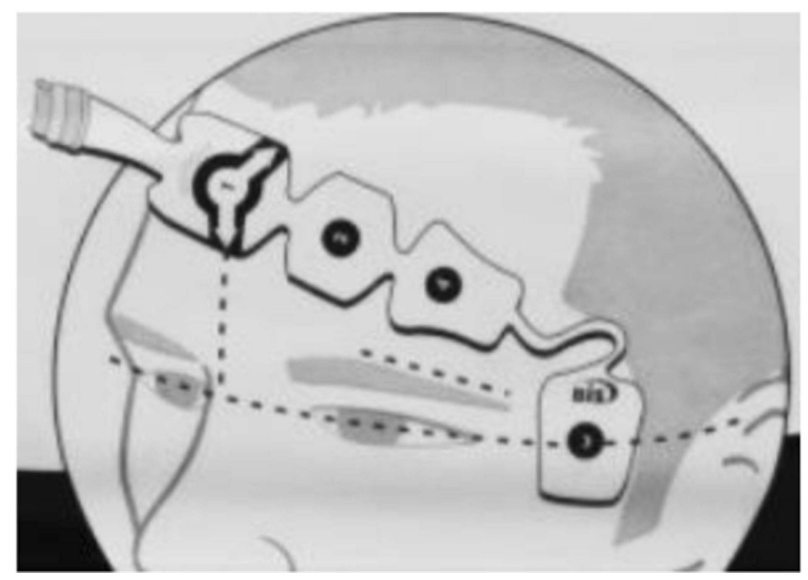

Figure I Positionof Bispectral Index monitoring electrodes.
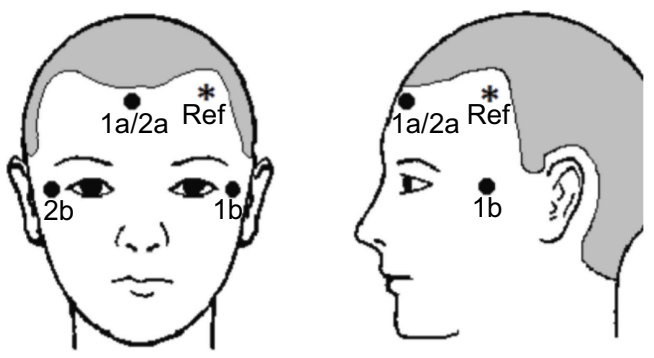

Figure 2 Positionof Narcotrend monitoring electrodes.

(EE-0203; Monitor Technik) were placed on the patient's forehead in accordance with the manufacturer's instructions. ${ }^{24,25}$ Figures 1 and 2 show the positioning of the BIS and Narcotrend electrodes. Once both monitors had been connected to the patient's electrodes, electrode impedance was checked and the times on the two monitors synchronised. Depth of anesthesia was recorded continuously throughout the surgery using a Narcotrend Compact M monitor (software version 2.0; Monitor Technik) and a rapid hemodynamic monitor (Lidco, London, UK) with an inbuilt BISx module (software version 4.0). Data were downloaded from both monitors at the end of each procedure to a password-protected computer in the research department and saved on a password-protected memory drive for subsequent analysis.

During the 8-week study period, data collection was attempted for 23 patients, but three were excluded from the analysis due to long periods of equipment malfunction.

BIS data were recorded with every heartbeat, while NCT data pairs were recorded at 5-second intervals. After BIS and NCT data had been matched, a total of 52,562 data pairs were obtained from 20 patients. A total of 46,300 artefact-free data pairs of BIS and NCT values 


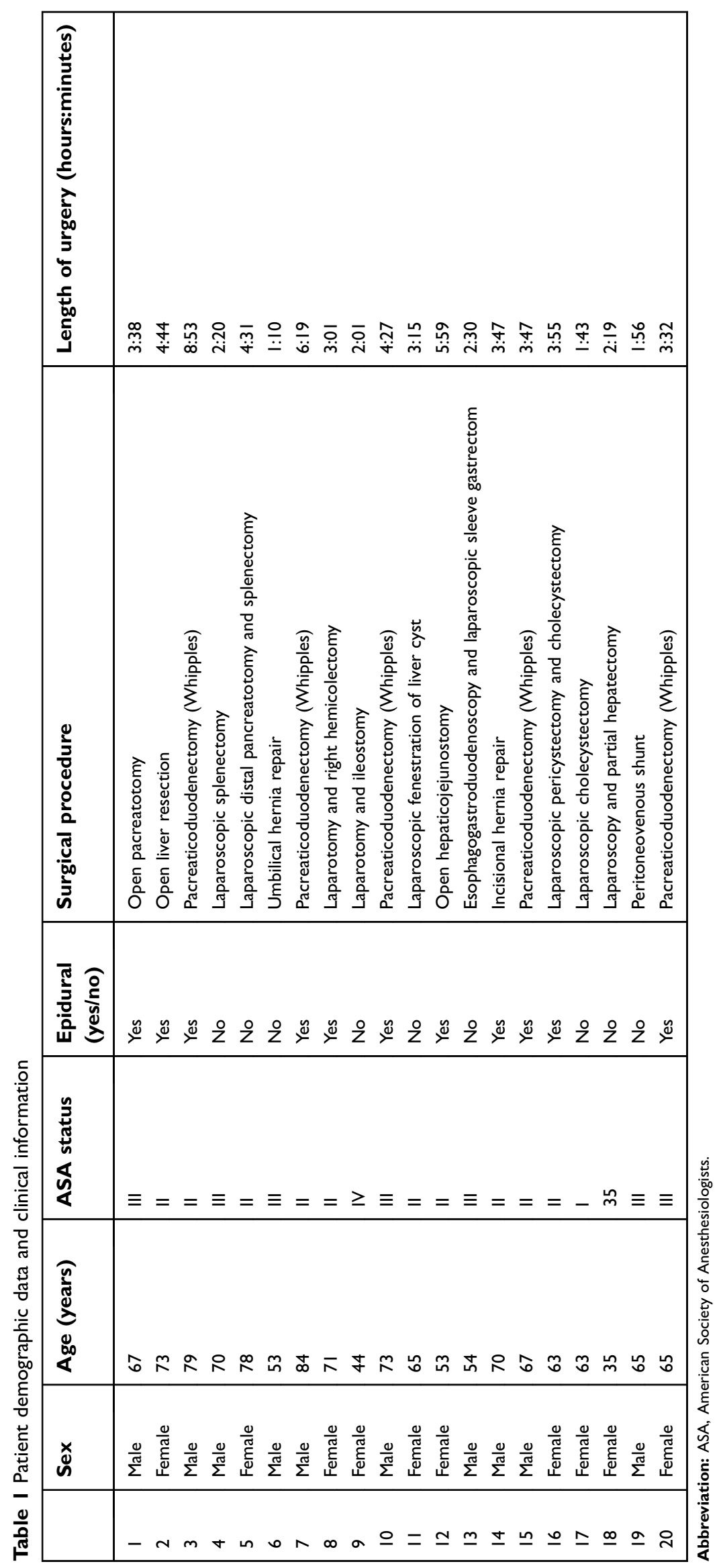


Table 2 Frequency distribution of total data pairs. Number and percentage (\%) of total data pairs

\begin{tabular}{|l|l|l|l|}
\hline \multirow{2}{*}{ Bispectral Index } & \multicolumn{2}{|l|}{ Narcotrend index } \\
\cline { 2 - 4 } & $\mathbf{0 - 2 6}$ below target range & $\mathbf{2 7 - 6 4}$ within target range & $\mathbf{6 5 - 1 0 0}$ above target range \\
\hline 0-39 below target range & $2,387(5.16)$ & $14,605(31.54)$ & $19(0.04)$ \\
$40-60$ within target range & $158(0.34)$ & $27,974(60.42)$ & $666(1.44)$ \\
$61-100$ above target range & $25(0.05)$ & $450(0.97)$ & $16(0.03)$ \\
\hline
\end{tabular}

were included in the analysis. Of these, $6,262(12 \%)$ data pairs were excluded from the analysis because one or both monitors failed to display an index value at a given time point. The BIS failed to display an index value at 281 (4\% of the total excluded) time points, and the NCT failed at 5,981 (96\% of the total excluded) time points. Each index was then categorized according to whether the value was below, within, or above the target range (40-60 for BIS and 27-64 for NCT).

Patient demographics and clinical details are shown in Table 1. The concordance of clinical guidance provided by the BIS and NCT during surgery was analyzed, and the results are presented in Table 2. Nine scenarios are shown as a contingency table indicating the frequency distribution of total data pairs obtained in the study. The scenarios summarised in $3 \times 3$ contingency tables for each patient are presented in Table S1. These include scenarios in which both indices were within, below, or above the range, when one index was below the range and the other within or above, and when one index was above the range and the other within or below.

Analysis of the data for all 20 patients indicated that the majority of observations $(30,377,57.7 \%)$ showed agreement, as both monitors had BIS and NCT measurements: the majority were within the target range (53.2\%), some below the target range $(4.5 \%)$ and very few below the target range $(<1 \%)$. Only $1.6 \%$ of the remaining data had disagreement between BIS and NCT readings. The largest disagreement was for $27.7 \%$ of data $(14,605)$ indicated to be within the target range according to the NCT, but below the target range according to the BIS.

We analyzed data for individual patients, as shown in Table S1. If $>55 \%$ of the data were in agreement, they were classified as showing good agreement. Based on this classification, only six of 20 showed good agreement.

Data pairs suggesting contradictory clinical guidance were identified in each patient. Representative examples are shown in Figure 3: patient 11 showed 90\% concordance between the two monitors, patient 8 showed $63 \%$ concordance, which was close to the mean value in our study, and patient 20 showed the lowest concordance rate of $6 \%$.

\section{Discussion}

The results of the present study suggested a high rate of failure to display an index value with the NCT monitor. This problem has also been highlighted in previous studies. ${ }^{22,26}$ The discrepancy varied between $23 \%$ and $45 \%$.

These results also suggested that the depths of anesthesia indices displayed by the BIS and NCT in patients undergoing major hepatobiliary surgery are not always comparable.

The highest rate of discrepancy, $27.7 \%$, was observed when the NCT was within the target, range but BIS monitoring data below the target range. Under such conditions, if we relied on BIS data, we would lighten anesthesia, which could leave the patients within or above the target range and potentially lead to their remaining conscious during anesthesia if we used the NCT as guidance.

It seemed that the potential to misguide clinicians may have been greater in particular groups of patients, but we cannot yet comment on the extent of this effect, due to a lack of data.

The time delay (14-155 seconds) of index calculation with these monitors may limit their value in prevention of recall of intraoperative events. ${ }^{27}$ Therefore, the discrepancy between readings may not be of huge clinical significance. In addition, the positions of BIS and NCT electrodes may have caused discrepancies in the results in some patients, eg, if they were too distant or too close to each other. However, we have no data regarding interreactions between electrodes.

The remaining $1.65 \%$ discrepancy has no clinical significance, as when using both monitors, we do not look at every data set individually but examine the area under the curve.

As suggested in other studies, comprehensive assessment of depth of anesthesia, including review of clinical signs, using a monitored anesthesia care-based technique must be carried out, in addition to using the indices provided by depth-of-anesthesia monitors during surgical procedures. ${ }^{27}$ 

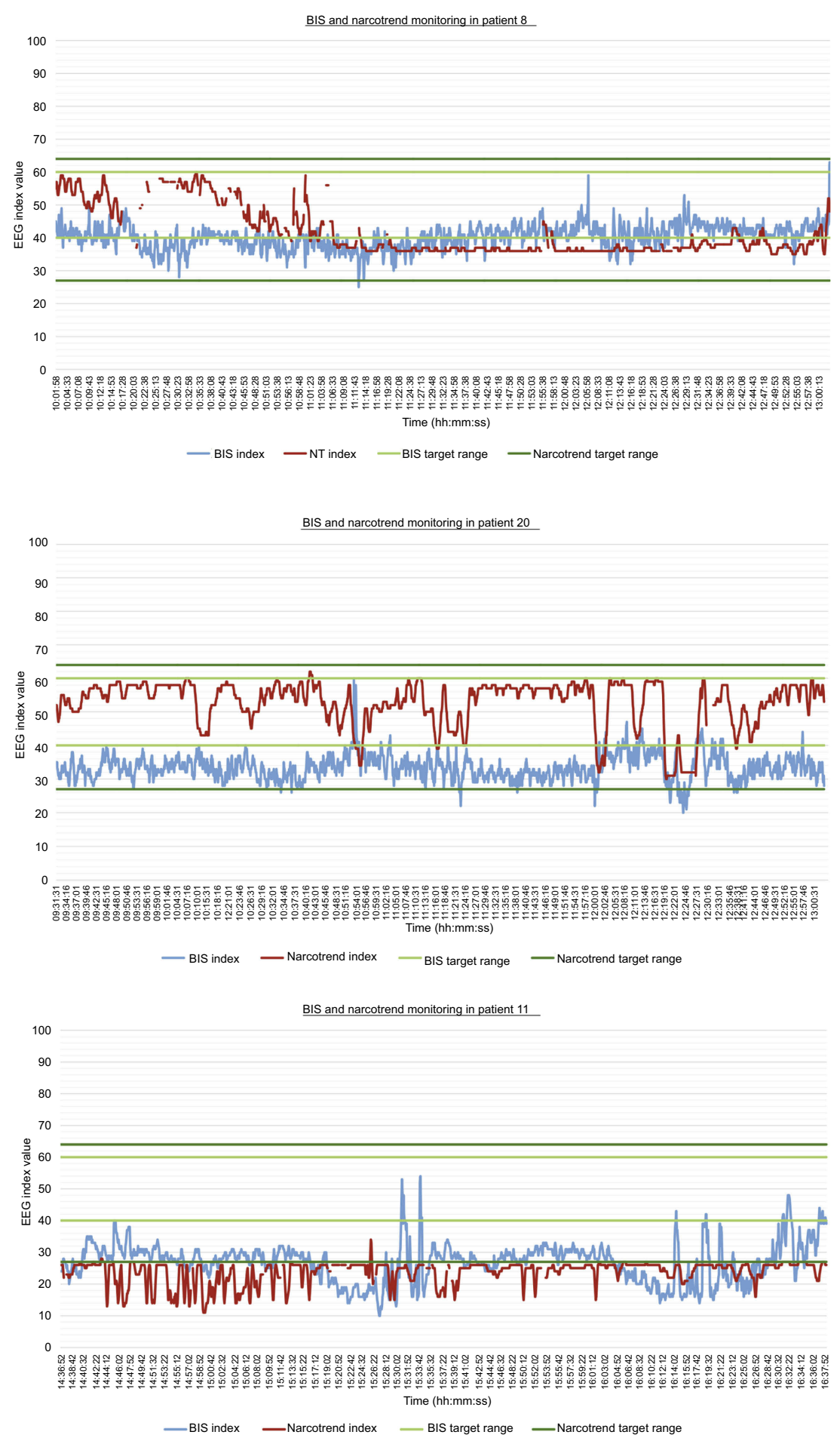

Figure 3 Representative examples.

Notes: Bispectral Index values plotted in blue and lower and upper limits for target range plotted in pale green. Narcotrend index values plotted in red and lower and upper limits for target range plotted in dark green. Gaps in trend line represent failure of monitor to record an index value.

Trend and waveform analyses of these EEG-based monitors may be more clinically useful. Willingham et al made similar recommendations in a recent editorial. They suggested that based on current evidence, it can no longer be considered safe or defensible to decrease anesthetic administration if depth-of-anesthesia monitors provide a potentially falsely reassuring value. ${ }^{28}$

This case series had certain limitations, including lack of standardization of anesthetic, lack of blinding of the anesthetist regarding BIS and NCT indices during 
anesthesia, small sample, and lack of patient-exclusion criteria. The failing rate of BIS and NCT indices numbers differs extremely, with no obvious reason. Therefore, we could not control for several variables that may have affected the accuracy of the monitors.

Further studies are required to assess the accuracy, reliability, and clinical implications of depth-of-anesthesia monitoring using various types of EEG-based monitors.

\section{Conclusion}

In this case series, we compared BIS and NCT EEG-based depth-of-anesthesia monitors in high-risk patients undergoing major hepatobiliary surgery. Our results indicated discordance in the clinical guidance provided by these monitors in $29.3 \%$ of cases. The delay in calculation time between the two monitors may have contributed to these findings. These observations mean that we cannot fully rely on EEG monitoring to determine the depth of anesthesia. Therefore, it is important for the anesthetist continually to perform comprehensive assessment of depth of anesthesia, including use of depth-of-anesthesia monitors, review of clinical signs, and use of monitored anesthesia care-based techniques where appropriate. In addition, monitoring of relative changes in the BIS:NCT index ratio over time would be more clinically useful than recording absolute values.

\section{Disclosure}

The authors report no conflicts of interest in this work.

\section{References}

1. Osterman JE, Hopper J, Heran WJ, Keane TM, van der Kolk BA. Awareness under anesthesia and the development of posttraumatic stress disorder. Gen Hosp Psychiatry. 2001;23:198-204. doi:10.1016/ S0163-8343(01)00142-6

2. Myles PS, Williams DL, Hendrata M, Anderson H, Weeks AM. Patient satisfaction after anaesthesia and surgery: results of a prospective survey of 10,811 patients. Br $J$ Anaesth. 2000;84:6-10. doi:10.1093/oxfordjournals.bja.a013383

3. Radtke FM, Franck M, Lendner J, Kruger S, Wernecke KD, Spies CD. Monitoring depth of anaesthesia in a randomized trial decreases the rate of postoperative delirium but not postoperative cognitive dysfunction. Br J Anaesth. 2013;110:i98-i105. doi:10.1093/bja/aet055

4. MT V C, Cheng BCP, Lee TMC, et al. BIS-guided anesthesia decreases postoperative delirium and cognitive decline. J Neurosurg Anesthesiol. 2013;25:33-42. doi:10.1097/ANA.0b013e3182712fba

5. Sessler DI, Sigl JC, Kelley SD, et al. Hospital stay and mortality are increased in patients having a "Triple low" of low blood pressure, low bispectral index, and low minimum alveolar concentration of volatile anesthesia. Anesthesiology. 2012;116:1195-1203. doi:10.1097/ ALN.0b013e31825683dc
6. Maheshwari A, McCormick PJ, Sessler DI, et al. Prolonged concurrent hypotension and low bispectral index ("double low") are associated with mortality, serious complications, and prolonged hospitalization after cardiac surgery. Br J Anaesth. 2017;119:40-49. doi:10.1093/bja/aex095

7. Myles $\mathrm{P}$, Leslie $\mathrm{K}$, McNeil J, et al. Bispectral index monitoring to prevent awareness during anaesthesia: the B-Aware randomised controlled trial. Lancet. 2004;363:1757-1763. doi:10.1016/S0140-6736 (04)16300-9

8. Avidan MS, Zhang L, Burnside BA, et al. Anesthesia awareness and the bispectral index. $N$ Engl $J$ Med. 2008;358:1097-1108. doi:10.1056/NEJMoa0707361

9. Mashour GA, Shanks A, Tremper KK, et al. Prevention of intraoperative awareness with explicit recall in an unselected surgical population. Anesthesiology. 2012;117:717-725. doi:10.1097/ ALN.0b013e31825a310c

10. Avidan MS, Jacobsohn E, Glick D, et al. Prevention of intraoperative awareness in a high risk surgical population. $N$ Engl $J$ Med. 2011;365:591-600. doi:10.1056/NEJMoa0910383

11. Leslie K, Short TG. Anesthetic depth and long-term survival: an update. Can J Anesth. 2016;63:233-240. doi:10.1007/s12630-0160620-3

12. Shepherd J, Jones J, Frampton GK, Bryant J, Baxter L, Cooper K. Effectiveness of depth of anaesthesia monitoring. Health Technol Assess (Rockv). 2013;17(3):34.

13. Checketts MR, Alladi R, Ferguson K, et al. Recommendations for standards of monitoring during anaesthesia and recovery. Anaesthesia. 2016;71:85-93. doi:10.1111/anae.13316

14. Depth of anaesthesia monitors - bispectral Index (BIS), E-Entropy and Nacrotrend Compact M. National Institute for Health and Clinical Excellence. Available from: https://www.nice.org.uk/gui dance/dg6/resources/depth-of-anaesthesia-monitors-bispectralindexbis-eentropy-and-narcotrendcompact-m-pdf-29275661509. Accessed January $28,2018$.

15. Schultz A, Siedenberg M, Grouven M, Kneif T, Schultz. B. Comparison of narcotrend index, spectral and entropy parameters during induction of Propofol-remifetanil anaesthesia. J Clin Monit Comput. 2008;22:103-111. doi:10.1007/s10877-008-9111-6

16. Kreuer S, Biedler A, Larsen R, Schoth S, Altmann S, Wilhelm W. The Narcotrend ${ }^{\mathrm{TM}}$ - a new EEG monitor designed to measure the depth of anaesthesia A comparison with bispectral index monitoring during propofol-remifentanil-anaesthesia. Anaesthesist. 2001;50:921925. doi:10.1007/s00101-001-0242-0

17. Schmidt G, Bischoff P, Standl T, Lankenau G, Hilbert M, Schulte J. Comparative Evaluation of Narcotrend ${ }^{\mathrm{TM}}$, Bispectral Index ${ }^{\mathrm{TM}}$, and classical electroencephalographic variables during induction, maintenance, and emergence of a propofol/remifentanil anesthesia. Anesth Analg. 2004;98:1346-1353.

18. Kreuer S, Bruhn J, Larsen R, Grundmann U, Shafer SL, Wilhelm W. Application of Bispectral Index ${ }^{\circledR}$ and Narcotrend ${ }^{\circledR}$ index to the measurement of the electroencephalographic effects of Isoflurane with and without burst suppression. Anesthesiology. 2004;101:847854. doi:10.1097/00000542-200410000-00008

19. Kreuer S, Wilhelm W, Grundmann U, Larsen R, Bruhn J. Narcotrend index versus bispectral index as electroencephalogram measures of anesthetic drug effect during propofol anesthesia. AnesthAnalg. 2004;98:692-697.

20. Wallenborn J, Kluba K, Olthoff D. Comparative evaluation of Bispectral Index and Narcotrend Index in children below 5 years of age. Pediatric Anesthesia. 2007;17:140-147. doi:10.1111/pan.2007.17.issue-2

21. Russell IF. The Narcotrend 'depth of anaesthesia' monitor cannot reliably detect consciousness during general anaesthesia: an investigation using the isolated forearm technique. Br J Anaesth. 2006;96 (3):346-352. doi:10.1093/bja/ael017 
22. Kreuer S, Bruhn J, Larsen R, Bialas P, Wilhelm W. Comparability of NarcotrendTM index and bispectral index during propofol anaesthesia. Br J Anaesth. 2004;93(2):235-240. doi:10.1093/bja/aeh182

23. Panousis P, Heller AR, Burghardt M, Bleyl JU, Koch T. The effects of electromyographic activity on the accuracy of the Narcotrend monitor compared with the Bispectral Index during combined anaesthesia. Anaesthesia. 2007;62:868-874. doi:10.1111/j.1365-2044.2007.05145.x

24. BIS VISTA Monitoring System: operator's manual. Covidien. Available from: http://www.covidien.com/imageServer.aspx/ doc225593.00.pdf?contentID $=24263 \&$ contenttype $=$ application $/ \mathrm{pdf}$ Accessed July 27, 2017.
25. Narcotrend Compact M operating instructions. MonitorTechnik. 2015.

26. Smith WD, Dutton RC, Smith NT. Measuring the performance of anesthetic depth indicators. Anesthesiology. 1996;84(1):38-51.

27. Pilge S, Zanner R, Schneider G, Blum J, Kreuzer M, Kochs EF. Time delay of index calculation: analysis of cerebral state, bispectral, and narcotrend indices. Anesthesiology. 2006;104(3):488494.

28. Willingham MD, Avidan MS. Triple low, double low: it's time to deal Achilles heel a single deadly blow. Br J Anaesth. 2017;119(1):1-4. 


\section{Supplementary material}

Table SI Frequency distribution of BIS and Narcotrend data pairs obtained per patient

\begin{tabular}{|c|c|c|c|c|}
\hline \multirow[t]{2}{*}{ Patient number } & \multirow[t]{2}{*}{ BIS index (\%) } & \multicolumn{3}{|c|}{ Narcotrend index (\%) } \\
\hline & & Low & In range & High \\
\hline 1 & $\begin{array}{l}\text { Low } \\
\text { In range } \\
\text { High }\end{array}$ & $\begin{array}{l}0 \\
0 \\
0\end{array}$ & $\begin{array}{l}784(33) \\
1,545(66) \\
2(<1)\end{array}$ & $\begin{array}{l}0 \\
10(<1) \\
0\end{array}$ \\
\hline 2 & $\begin{array}{l}\text { Low } \\
\text { In range } \\
\text { High }\end{array}$ & $\begin{array}{l}169(7) \\
30(1) \\
0\end{array}$ & $\begin{array}{l}1,853(72) \\
539(20) \\
0\end{array}$ & $\begin{array}{l}0 \\
0 \\
0\end{array}$ \\
\hline 3 & $\begin{array}{l}\text { Low } \\
\text { In range } \\
\text { High }\end{array}$ & $\begin{array}{l}|5|(3) \\
14(<1) \\
0\end{array}$ & $\begin{array}{l}187(3) \\
4,997(87) \\
2(<1)\end{array}$ & $\begin{array}{l}7(<1) \\
396(7) \\
0\end{array}$ \\
\hline 4 & $\begin{array}{l}\text { Low } \\
\text { In range } \\
\text { High }\end{array}$ & $\begin{array}{l}0 \\
0 \\
0\end{array}$ & $\begin{array}{l}153(10) \\
1,392(90) \\
0\end{array}$ & $\begin{array}{l}0 \\
0 \\
0\end{array}$ \\
\hline 5 & $\begin{array}{l}\text { Low } \\
\text { In range } \\
\text { High }\end{array}$ & $\begin{array}{l}0 \\
3(<1) \\
0\end{array}$ & $\begin{array}{l}924(29) \\
2,3 \mid 3(7 I) \\
I(<I)\end{array}$ & $\begin{array}{l}0 \\
0 \\
0\end{array}$ \\
\hline 6 & $\begin{array}{l}\text { Low } \\
\text { In range } \\
\text { High }\end{array}$ & $\begin{array}{l}0 \\
0 \\
0\end{array}$ & $\begin{array}{l}160(20) \\
654(80) \\
0\end{array}$ & $\begin{array}{l}0 \\
0 \\
0\end{array}$ \\
\hline 7 & $\begin{array}{l}\text { Low } \\
\text { In range } \\
\text { High }\end{array}$ & $\begin{array}{l}0 \\
0 \\
0\end{array}$ & $\begin{array}{l}574(22) \\
2,038(77) \\
6(<1)\end{array}$ & $\begin{array}{l}2(<1) \\
30(1) \\
0\end{array}$ \\
\hline 8 & $\begin{array}{l}\text { Low } \\
\text { In range } \\
\text { High }\end{array}$ & $\begin{array}{l}0 \\
0 \\
0\end{array}$ & $\begin{array}{l}712(37) \\
1,227(63) \\
2(<1)\end{array}$ & $\begin{array}{l}0 \\
0 \\
0\end{array}$ \\
\hline 9 & $\begin{array}{l}\text { Low } \\
\text { In range } \\
\text { High }\end{array}$ & $\begin{array}{l}1,285(92) \\
30(2) \\
0\end{array}$ & $\begin{array}{l}72(5) \\
13(1) \\
0\end{array}$ & $\begin{array}{l}0 \\
0 \\
0\end{array}$ \\
\hline 10 & $\begin{array}{l}\text { Low } \\
\text { In range } \\
\text { High }\end{array}$ & $\begin{array}{l}108(3) \\
26(1) \\
0\end{array}$ & $\begin{array}{l}\mathrm{I}, 562(49) \\
\mathrm{I}, 452(46) \\
\mathrm{I}(<\mathrm{I})\end{array}$ & $\begin{array}{l}10(<1) \\
7(<1) \\
0\end{array}$ \\
\hline 11 & $\begin{array}{l}\text { Low } \\
\text { In range } \\
\text { High }\end{array}$ & $\begin{array}{l}195(9) \\
16(1) \\
25(1)\end{array}$ & $\begin{array}{l}67 \mid(32) \\
\mathrm{I}, 20 \mathrm{I}(57) \\
0\end{array}$ & $\begin{array}{l}0 \\
8(<1) \\
0\end{array}$ \\
\hline 12 & $\begin{array}{l}\text { Low } \\
\text { In range } \\
\text { High }\end{array}$ & $\begin{array}{l}0 \\
0 \\
0\end{array}$ & $\begin{array}{l}93(3) \\
3,108(96) \\
47(1)\end{array}$ & $\begin{array}{l}0 \\
0 \\
0\end{array}$ \\
\hline 13 & $\begin{array}{l}\text { Low } \\
\text { In range } \\
\text { High }\end{array}$ & $\begin{array}{l}0 \\
0 \\
0\end{array}$ & $\begin{array}{l}215(12) \\
1,27 \mid(73) \\
129(7)\end{array}$ & $\begin{array}{l}0 \\
117(7) \\
10(1)\end{array}$ \\
\hline
\end{tabular}

(Continued) 
Table SI (Continued).

\begin{tabular}{|c|c|c|c|c|}
\hline \multirow[t]{2}{*}{ Patient number } & \multirow[t]{2}{*}{ BIS index (\%) } & \multicolumn{3}{|c|}{ Narcotrend index (\%) } \\
\hline & & Low & In range & High \\
\hline 14 & $\begin{array}{l}\text { Low } \\
\text { In range } \\
\text { High }\end{array}$ & $\begin{array}{l}0 \\
0 \\
0\end{array}$ & $\begin{array}{l}476(2 I) \\
I, 694(76) \\
0\end{array}$ & $\begin{array}{l}0 \\
53(2) \\
0\end{array}$ \\
\hline 15 & $\begin{array}{l}\text { Low } \\
\text { In range } \\
\text { High }\end{array}$ & $\begin{array}{l}149(6) \\
15(<1) \\
0\end{array}$ & $\begin{array}{l}I, 717(67) \\
627(24) \\
68(3)\end{array}$ & $\begin{array}{l}0 \\
0 \\
0\end{array}$ \\
\hline 16 & $\begin{array}{l}\text { Low } \\
\text { In range } \\
\text { High }\end{array}$ & $\begin{array}{l}8 I(3) \\
0 \\
0\end{array}$ & $\begin{array}{l}38(I) \\
2,410(88) \\
164(6)\end{array}$ & $\begin{array}{l}0 \\
45(2) \\
6(<1)\end{array}$ \\
\hline 17 & $\begin{array}{l}\text { Low } \\
\text { In range } \\
\text { High }\end{array}$ & $\begin{array}{l}24 \mathrm{I}(22) \\
24(2) \\
0\end{array}$ & $\begin{array}{l}736(68) \\
81(8) \\
0\end{array}$ & $\begin{array}{l}0 \\
0 \\
0\end{array}$ \\
\hline 18 & $\begin{array}{l}\text { Low } \\
\text { In range } \\
\text { High }\end{array}$ & $\begin{array}{l}0 \\
0 \\
0\end{array}$ & $\begin{array}{l}\text { I,033(64) } \\
585(36) \\
0\end{array}$ & $\begin{array}{l}0 \\
0 \\
0\end{array}$ \\
\hline 19 & $\begin{array}{l}\text { Low } \\
\text { In range } \\
\text { High }\end{array}$ & $\begin{array}{l}8(I) \\
0 \\
0\end{array}$ & $\begin{array}{l}269(27) \\
686(69) \\
28(3)\end{array}$ & $\begin{array}{l}0 \\
0 \\
0\end{array}$ \\
\hline 20 & $\begin{array}{l}\text { Low } \\
\text { In range } \\
\text { High }\end{array}$ & $\begin{array}{l}0 \\
0 \\
0\end{array}$ & $\begin{array}{l}2,376(94) \\
|4|(6) \\
0\end{array}$ & $\begin{array}{l}0 \\
0 \\
0\end{array}$ \\
\hline
\end{tabular}

Note: Number of data pairs and percentage of total data pairs per patient rounded to the nearest whole number.

\section{Clinical Audit}

\section{Publish your work in this journal}

Clinical Audit is an international, peer-reviewed, open access journal focusing on the processes and outcomes of clinical audit in any area of healthcare. All aspects of patient care are addressed within the journal and practitioners from all disciplines are invited to submit their work. Areas covered include: Publication of audits; How an audit has changed practice; Practical tips on how to do audits and to avoid pitfalls; How audits have changed patient care; Calls and justifications for new audits. The manuscript management system is completely online and includes a very quick and fair peer-review system, which is all easy to use. Visit http://www.dovepress.com/ testimonials.php to read real quotes from published authors. 